\title{
Protective effect of curcumin against ultraviolet $A$ irradiation-induced photoaging in human dermal fibroblasts
}

\author{
XIAOMING LIU ${ }^{1}$, RUIZHI ZHANG ${ }^{1}$, HAIXIA SHI ${ }^{1}$, XIAOBO LI $^{2,5}$, \\ YANHONG LI ${ }^{3}$, AHMAD TAHA ${ }^{4}$ and CHUNXING XU ${ }^{1}$ \\ ${ }^{1}$ Department of Dermatology, The Third Affiliated Hospital of Soochow University, Changzhou, \\ Jiangsu 213003; ${ }^{2}$ Urumqi Jinsuijian Technical Development Co., Ltd., Urumqi, Xinjiang 830013; \\ ${ }^{3}$ Xinjiang Key Laboratory of Special Species Conservation and Regulatory Biology, College of Life Science, \\ Xinjiang Normal University, Urumqi, Xinjiang 830054, P.R. China; ${ }^{4}$ Faculty of Medicine, \\ Department of Medicine, SEGi University, Petaling Jaya, Selangor 47810, Malaysia
}

Received September 26, 2017; Accepted February 13, 2018

DOI: $10.3892 / \mathrm{mmr} .2018 .8791$

\begin{abstract}
Ultraviolet (UV) radiation induces DNA damage, oxidative stress, and inflammatory processes in skin, resulting in photoaging. Natural botanicals have gained considerable attention due to their beneficial protection against the harmful effects of UV irradiation. The present study aimed to evaluate the ability of curcumin (Cur) to protect human dermal fibroblasts (HDFs) against ultraviolet A (UVA)-induced photoaging. HDFs were treated with $0-10 \mu \mathrm{M}$ Cur for $2 \mathrm{~h}$ and subsequently exposed to various intensities of UVA irradiation. The cell viability and apoptotic rate of HDFs were investigated by MTT and flow cytometry assays, respectively. The effect of UVA and Cur on the formation of reactive oxygen species (ROS), malondialdehyde levels, which are an indicator of ROS, and the levels/activity of antioxidative defense proteins, including glutathione, superoxide dismutase and catalase, were evaluated using 2',7'-dichlorofluorescin diacetate and commercial assay kits. Furthermore, western blotting was performed to determine the levels of proteins associated with endoplasmic reticulum (ER) stress, the apoptotic pathway, inflammation and the collagen synthesis pathway. The results demonstrated that Cur reduced the accumulation of ROS and restored the
\end{abstract}

Correspondence to: Dr Xiaoming Liu, Department of Dermatology, The Third Affiliated Hospital of Soochow University, 185 Juqian Street, Changzhou, Jiangsu 213003, P.R. China

E-mail: xiaomingliu2012@163.com

Dr Xiaobo Li, Urumqi Jinsuijian Technical Development Co., Ltd., 91 Beijing North Road, Urumqi, Xinjiang 830013, P.R. China E-mail:1_xb@outlook.com

Present address: ${ }^{5}$ Department of Pathology and Laboratory Medicine, Perelman School of Medicine, University of Pennsylvania, Philadelphia, PA 19104, USA.

Key words: curcumin, ultraviolet A, reactive oxygen species, endoplasmic reticulum stress, apoptosis, transforming growth factor- $\beta$ activity of antioxidant defense enzymes, indicating that Cur minimized the damage induced by UVA irradiation in HDFs. Furthermore, western blot analysis demonstrated that Cur may attenuate UVA-induced ER stress, inflammation and apoptotic signaling by downregulating the protein expression of glucose-regulated protein 78, C/EBP-homologous protein, nuclear factor- $\mathrm{\kappa B}$ and cleaved caspase-3, while upregulating the expression of $\mathrm{Bcl}-2$. Additionally, it was demonstrated that Cur may regulate collagen metabolism by decreasing the protein expression of matrix metalloproteinase (MMP)-1 and MMP-3, and may promote the repair of cells damaged as a result of UVA irradiation through increasing the protein expression of transforming growth factor- $\beta$ (TGF- $\beta$ ) and $\operatorname{Smad} 2 / 3$, and decreasing the expression of the TGF- $\beta$ inhibitor, Smad7. In conclusion, the results of the present study indicate the potential benefits of Cur for the protection of HDFs against UVA-induced photoaging and highlight the potential for the application of Cur in skin photoprotection.

\section{Introduction}

Ultraviolet (UV) radiation is one of the major physical stress factors that affect the human skin. UV radiation from the sun is composed of a broad spectrum, including short-wave UVC (200-280 nm), mid-wave UVB (280-320 nm) and long-wave UVA (320-400 nm). UVC is absorbed by the stratospheric ozone layer, which means that its contribution to human skin pathogenesis is minimal. However, UVB is considered to be highly biologically active and is an established high-risk factor for skin carcinogenesis, particularly malignant melanoma $(1,2)$. Accounting for $95 \%$ of the solar UV light, UVA is primarily responsible for photoaging, which is characterized by wrinkles, and loss of skin tone and elasticity (3). However, certain reports have demonstrated that UVA is more penetrating than UVB and reaches the subcutaneous tissue to exert effects on dermal and epidermal skin structures $(4,5)$. Furthermore, an increasing amount of evidence indicates that the majority of basal cell carcinomas may be primarily attributed to UVA irradiation $(4,5)$. To protect human dermal fibroblasts (HDFs) against the harmful effects of UVA, natural 
compounds are often employed, including Coenzyme Q10, vitamin C, vitamin E and Amaranth Oil (6-8).

Curcumin (Cur), a bioactive photochemical that is extracted from the rhizome of Curcuma longa Lin., has been previously employed for the treatment of skin diseases and wound healing in traditional Chinese medicine (9-11). Furthermore, increasing scientific evidence has demonstrated that Cur is able to inhibit chemical-induced carcinogenesis/tumor promotion and radiation-induced mammary tumorigenesis (12-15). In addition, a molecular biology-based study demonstrated that Cur may exert inhibitory effects on the UVB-induced production of reactive oxygen species (ROS) and expression of matrix metalloproteinase (MMP) in vitro by blocking the activation of the UVB-induced mitogen-activated protein kinase, nuclear factor- $\kappa \mathrm{B}(\mathrm{NF}-\kappa \mathrm{B})$ and $\mathrm{AP}-1$ transcription factor signal pathways (16). Tsai et al (17) demonstrated that Cur provided protection against UVB radiation-induced skin cancer growth in a mouse model. Li et al (18) reported that Cur may have potential as a chemoprotective agent against skin carcinogenesis in vivo and in vitro. However, research concerning the protective effect of Cur against UVA is limited and the molecular mechanisms underlying this protective effect against UVA have not been detailed.

The purpose of the present study was to evaluate the protective effects and investigate the underlying mechanisms of Cur against UVA damage in HDFs in vitro. An improved understanding of the protective properties of Cur may allow the development of more efficient therapeutic approaches for preventing the photoaging of skin and promoting UVA-induced fibroblast repair.

\section{Materials and methods}

Reagents and antibodies. Cur (99\% purity) was obtained from Sigma-Aldrich (Merck KGaA, Darmstadt, Germany) and dissolved in dimethyl sulfoxide (DMSO) as a $10 \mathrm{mmol} / \mathrm{l}$ stock solution and stored at $-20^{\circ} \mathrm{C}$. MTT and DMSO were purchased from Sigma-Aldrich (Merck KGaA). Dulbecco's modified Eagle medium (DMEM), fetal bovine serum (FBS), penicillin and streptomycin were purchased from Gibco (Thermo Fisher Scientific, Inc., Waltham, MA, USA). The Annexin V-Fluorescein isothiocyanate (FITC) Apoptosis Detection kit and was purchased from BD Biosciences (San Jose, CA, USA). Primary antibodies against transforming growth factor- $\beta$ (TGF- $\beta$; rabbit; cat. no. ab50716; $1: 400$ ), $\beta$-actin (rabbit; cat. no. ab8227; 1:5,000), NF-кB p65 (rabbit; cat. no. ab16502; 1:2,000), MMP-3 (rabbit; cat. no. ab52915; 1:2,000), Bcl-2 (rabbit; cat. no. ab59348; 1:1,000), caspase-3 (rabbit; cat. no. ab4051; 1:500) and anti-glucose-regulated protein 78 (GRP78; rabbit; catalog no. ab21685; 1:1,000) were purchased from Abcam (Cambridge, MA, USA). The antibody against MMP-1 (human, cat.no. AF901; 1:1,000) was purchased from Bio-Techne (Minneapolis, MN, USA). The antibody against Smad2/3 (rabbit; cat. no. 3102; 1:1,000) was purchased from Cell Signaling Technology, Inc., (Danvers, MA, USA). Smad7 polyclonal antibody (rabbit; cat. no. PA1-41506; 1:200 and $\mathrm{C} / \mathrm{EBP}$-homologous protein $(\mathrm{CHOP})$ monoclonal antibody (9C8; mouse; cat. no. MA1-250; 1:1,000) were purchased from Thermo Fisher Scientific, Inc.. Horseradish peroxidase-conjugated anti-rabbit IgG (cat. no. sc-2357; 1:5,000) and anti-mouse IgG (cat. no. sc-516102; 1:5,000) secondary antibodies were purchased from Santa Cruz Biotechnology, Inc., (Dallas, TX, USA). N-acetyl cysteine (NAC) and 4-phenylbutyric acid (4-PBA) were obtained from Sigma-Aldrich (Merck $\mathrm{KGaA}$ ) and were dissolved in deionized water as a $50 \mathrm{mmol} / 1$ stock solution. The stock solutions $(50 \mathrm{~mm})$ were diluted with PBS to the desired final concentration prior to use and subsequently added to the cell culture medium.

Cell culture. HDFs were isolated from the foreskin of a 5-year-old old boy undergoing circumcision at The Third Affiliated Hospital of Soochow University (Changzhou, China). The study was approved by the ethics committee of Soochow University and written informed consent was obtained from the parent of the child. The foreskin was digested with dispase solution $(5 \mathrm{mg} / \mathrm{ml})$ at $4^{\circ} \mathrm{C}$. After $16 \mathrm{~h}$ of incubation, the epidermal layer was removed and the dermis was cut into small pieces $\left(\sim 2 \mathrm{~mm}^{3}\right)$. Dermal explants were allowed to adhere to $25 \mathrm{~cm}^{2}$ culture flasks containing complete Dulbecco's modified Eagle's medium (DMEM), which consisted of DMEM supplemented with $10 \%$ FBS, $100 \mathrm{U} / \mathrm{ml}$ penicillin and $100 \mu \mathrm{g} / \mathrm{ml}$ streptomycin and $50 \mu \mathrm{g} / \mathrm{ml}$ amphotericin solution (all from Invitrogen; Thermo Fisher Scientific, Inc.), for $30 \mathrm{~min}$ at $37^{\circ} \mathrm{C}$ in an incubator. Following incubation of cells in a $\mathrm{CO}_{2}$-regulated incubator at $37^{\circ} \mathrm{C}$ under $5 \% \mathrm{CO}_{2}$ with $95 \%$ relative humidity for 2 weeks, fibroblasts reached confluence and were detached with trypsin-EDTA solution and passaged. The cells were observed under the inverted microscope (Olympus IX51; Olympus Inc., Tokyo, Japan) and demonstrated spindle-shape morphology with bipolar projections and were refractile. The cultured cells were further identified by immunocytochemistry. The cover-slips carrying cultured cells were washed two times with ice-cold PBST (PBS containing $1 \%$ Triton X-100) and then fixed with $4 \%$ paraformaldehyde in ice-cold PBS for $10 \mathrm{~min}$ at room temperature. The cells were then blocked with $4 \%$ bovine serum albumin (BSA) dissolved in PBST for $30 \mathrm{~min}$ at room temperature and stained with anti-viemtin (rabbit, cat. no. ab137321; 1:200; Abcam) or anti-cytokeratin 10 (CK10) antibodies (rabbit, cat. no. ab76318; 1:200; Abcam) at $4^{\circ} \mathrm{C}$ overnight. After washed three times with PBS, incubated with secondary antibodies horseradish peroxidase-conjugated anti-rabbit IgG (cat. no. sc-2357; 1:5,000; Santa Cruz Biotechnology, Inc.) and anti-mouse IgG (cat. no. sc-516102; 1:5,000; Santa Cruz Biotechnology, Inc.) in dark at room temperature for $30 \mathrm{~min}$. Washed with PBS three times, the DAB staining was performed at temperature according to the DAB kit (cat. no. AR 0611, 20 x, Beijing Dingguo Changsheng Biotechnology Co., Ltd., Beijing, China). Following $5 \mathrm{~min}$, the cells washed with double distilled water to end the DAB staining, then stained with HE. With inverted microscope (magnification $\mathrm{x} 400$, Olympus IX51; Olympus Inc., Tokyo, Japan), the immunocytochemistry demonstrated that the cells were positive for vimentin (dark brown) and negative for cytokeratin 10 (blue). The cells were confirmed as fibroblasts. Fibroblasts in the log phase of growth were used in all experiments in the present study.

UVA irradiation. Fibroblasts were seeded at a density of $3 \times 10^{5}$ cells in 6-well plates and were incubated inDMEM complete medium for $24 \mathrm{~h}$ at $37^{\circ} \mathrm{C}$, followed by incubation in serum-free 
DMEM containing a final concentration of $0,2.5,5$ or $10 \mu \mathrm{M}$ Cur in DMSO (final DMSO concentration, $0.1 \%$ ) at $37^{\circ} \mathrm{C}$. After $2 \mathrm{~h}$, the cells were washed twice with PBS and covered with a thin layer of PBS. Cells were subsequently exposed to various intensities of UVA irradiation $\left(5 \mathrm{~J} / \mathrm{cm}^{2}\right.$ for $17 \mathrm{~min}, 10 \mathrm{~J} / \mathrm{cm}^{2}$ for $33 \mathrm{~min}$ or $15 \mathrm{~J} / \mathrm{cm}^{2}$ for $51 \mathrm{~min}$ ). During exposure, the plate was placed on ice in order to reduce the effect of heat. The UVA source used in the experiment was a UV phototherapy instrument (SS-04A; Shanghai Sigma High-tech Co., Ltd., Shanghai, China) equipped with a 15-W ozone-free UVA lamp (CEL015 W; Philips, Groningen, The Netherlands) with a peak emission at $350 \mathrm{~nm}$. UVA radiation was uniformly exposed to samples at a distance of $15 \mathrm{~cm}$ from the cell cultures and the intensity of UVA was calibrated with a digital radiometer (Shanghai Sigma High-Tech Co., Ltd.). The cells were divided into the following four groups: Control group, which was cultured in regular medium and without any treatment; Cur group, which was only treated with Cur (5 $\mu \mathrm{M}$ for $2 \mathrm{~h})$; UVA irradiation group, which was treated with UVA alone $\left(10 \mathrm{~J} / \mathrm{cm}^{2}\right.$ for $\left.33 \mathrm{~min}\right)$; and Cur + UVA irradiation group, which was pre-incubated with Cur (5 $\mu \mathrm{M}$ for $2 \mathrm{~h}$ ) and subsequently exposed to UVA $\left(10 \mathrm{~J} / \mathrm{cm}^{2}\right.$ for $33 \mathrm{~min})$. For the positive control groups, the cells were pre-incubated either with NAC ( $5 \mathrm{mM}$ for $2 \mathrm{~h}$ ) or 4-PBA $(5 \mathrm{mM}$ for $2 \mathrm{~h})$ and then exposed to UVA (10 J/ $\mathrm{cm}^{2}$ for $\left.33 \mathrm{~min}\right)$. After UVA irradiation, the MTT, transmission electron microscopy (TEM), ROS, malondiadehyde (MDA), catalase (CAT) and glutathione (GSH) assays were performed immediately. For the apoptosis and western blotting analysis, cells were further incubated in complete DMEM for $24 \mathrm{~h}$ under standard conditions without rinsing following the irradiation.

MTT assay. Cell viability was examined using MTT assays. Briefly, cells were seeded in 96-well plates at a density of $1 \times 10^{4}$ cells/well and incubated at $37^{\circ} \mathrm{C}$ overnight. Treatments were performed as described above and the cells were immediately incubated with $100 \mu \mathrm{l}$ serum-free DMEM containing $10 \mu \mathrm{l}$ $\operatorname{MTT}(5 \mathrm{mg} / \mathrm{ml})$ at $37^{\circ} \mathrm{C}$ for $2 \mathrm{~h}$. Subsequently, the medium was replaced with $100 \mu \mathrm{l}$ DMSO. Following incubation for $20 \mathrm{~min}$ at room temperature, the absorbance was read by measuring the optical density (OD) at $490 \mathrm{~nm}$ in a microplate reader(Molecular Devices, LLC, Sunnyvale, CA, USA). The 50\% inhibitory concentration $\left(\mathrm{IC}_{50}\right)$ was calculated as follows: Inhibition rate $(\%)=\left(O D 490_{\text {Cur }}-\right.$ OD $\left.490_{\text {blank }}\right) /\left(\right.$ OD $490_{\text {control }}$ OD $\left.490_{\text {blank }}\right) \times 100$. Inhibition curves were drawn and the $\mathrm{IC}_{50}$ value of Cur was calculated. The experiment was repeated three times.

TEM. HDFs in control, Cur, UVA and Cur + UVA groups were harvested and fixed with $2.5 \%(\mathrm{v} / \mathrm{v})$ glutaraldehyde for $24 \mathrm{~h}$ at $4^{\circ} \mathrm{C}$, collected by centrifugation $\left(200 \times \mathrm{g}, 4^{\circ} \mathrm{C}\right.$ for $\left.5 \mathrm{~min}\right)$ and washed twice with cold PBS. All samples were post-fixed in $1 \%$ osmium tetroxide in $0.1 \mathrm{M}$ phosphate buffer $(\mathrm{pH} 7.2)$ at $4^{\circ} \mathrm{C}$ for $1 \mathrm{~h}$, dehydrated through a graded ethanol series and embedded in Epon 812 at $60^{\circ} \mathrm{C}$ for $48 \mathrm{~h}$. Ultrathin sections ( $70-\mathrm{nm})$ were cut and stained with $0.5 \%$ uranyl acetate for $15 \mathrm{~min}$ and $3 \%$ lead citrate for $5 \mathrm{~min}$ at room temperature and examined under a transmission electron microscope (Tecnai G2; Thermo Fisher Scientific, Inc.).

UVA-induced cellular apoptosis. Cell apoptosis was analyzed by an Annexin V-FITC Apoptosis Detection kit
(BD Biosciences) according to the manufacturer's protocol. HDF cells $\left(5 \times 10^{5}\right)$ were seeded in $60-\mathrm{mm}$ dishes and grew for $24 \mathrm{~h}$, then pre-incubated with or without $\operatorname{Cur}(5 \mu \mathrm{M})$ for $2 \mathrm{~h}$. After UVA irradiation, cells were collected by trypsinization and washed twice in cold phosphate-buffered saline (PBS). Cells $\left(1.0 \times 10^{6} / \mathrm{ml}\right)$ were added to $1 \mathrm{X}$ combination buffer $(100 \mu \mathrm{l})$. A total of $5 \mu \mathrm{l}$ Annexin $\mathrm{V}$ and $10 \mu \mathrm{l}$ propidium iodide were then added. The mixture was vortex-mixed and incubated in the dark for $15 \mathrm{~min}$ at room temperature. Loading buffer $(300 \mu \mathrm{l})$ was then added. Flow cytometry was then employed using a FACS Calibur flow cytometer (BD Biosciences). A minimum of 10,000 cells per sample was required and analyzed. All experiments were conducted 3 times. The data was analyzed by the BD FACStation software (2007; BD Biosciences).

Assessment of the intracellular levels of ROS. Intracellular ROS levels were measured using the fluorogenic compound, 2',7'-dichlorofluorescin diacetate $\left(\mathrm{H}_{2} \mathrm{DCFDA}\right.$; EMD Millipore, Billerica, MA, USA). The $1.5 \times 10^{4}$ cells were seeded in 96 well plates and incubated for $30 \mathrm{~min}$ at $37^{\circ} \mathrm{C}$ with $\mathrm{H}_{2}$ DCFDA at a final concentration of $40 \mu \mathrm{M}$ in the dark. When the non-fluorescent ester $\mathrm{H}_{2}$ DCFDA penetrates into cells and undergoes deacetylation to dichloro-dihydro-fluorescein (DCFH) by cellular esterases, the DCFH probe is rapidly oxidized to the highly fluorescent compound 2',7'-dichlorofluorescin by ROS. The fluorescence intensity was measured using a microplate fluorescence reader (excitation wavelength $488 \mathrm{~nm}$ and emission wavelength $521 \mathrm{~nm}$; SpectraMax M3; Molecular Devices, LLC).

Measurement of the activities of superoxide dismutase (SOD) and CAT, and the levels of MDA and GSH. The activities of SOD, CAT, MDA and GSH were measured by SOD assay kit (WST-1 method; cat. no. A001-3), CAT assay kit (Ultraviolet method; cat. no. A007-2), Cell MDA assay kit (colorimetric method; cat. no. A003-4) and reduced GSH assay kit (colorimetric method; cat. no. A006-2), respectively. All assays were conducted according to the manufacturer's protocols (Nanjing Jiancheng Bioengineering Institute, Nanjing, China).

Western blotting. Western blot analysis was performed to investigate protein expression. Cells cultured in 6-well plates were washed with PBS twice and harvested on the floor of the plate. Cells were lysed using radioimmunoprecipitation assay lysis buffer (Sigma-Aldrich; Merck KGaA) supplemented with a protease inhibitor cocktail (Roche Diagnostics, Indianapolis, IN, USA). Cell lysates were centrifuged at $13,000 \mathrm{x} \mathrm{g}$ for $15 \mathrm{~min}$ at $4^{\circ} \mathrm{C}$ and protein concentration was determined with a BCA assay. Samples $(10 \mu \mathrm{g}$ protein) were loaded onto $10 \%$ SDS-PAGE gels. Gel proteins were electrophoretically transferred to polyvinylidene difluoride membranes (PVDF; Thermo Fisher Scientific, Inc.). Membranes were blocked with $3 \%$ non-fat dried milk in PBS at $4^{\circ} \mathrm{C}$ overnight. Subsequently, PVDF membranes were incubated with specific primary antibody solutions against antigens for $24 \mathrm{~h}$ at $4^{\circ} \mathrm{C}$. Detection of the primary antibodies was performed using secondary, horseradish peroxidase-conjugated antibodies (Santa Cruz Biotechnology, Inc.). Details of the antibodies used have been provided earlier in the manuscript. Finally, the antigen-antibody complexes were visualized by a Pierce ECL 
Western Blotting Substrate (Thermo Fisher Scientific, Inc.; cat. no: 32106) and quantitated using the Versa DOC system and Quantity One software (\#1709600; Bio-Rad Laboratories, Inc., Hercules, CA, USA).

Statistical analysis. Statistical analysis was performed with SPSS version 18.0 (SPSS, Inc., Chicago, IL, USA). Data are presented as the mean \pm standard deviation of three independent experiments. The data were analyzed with one-way analysis of variance, followed by Dunnett's test and Tukey's test. For all tests, $\mathrm{P}<0.05$ was considered to indicate a statistically significant difference.

\section{Results}

Cur inhibits UVA-induced damage in HDFs. Pre-experimental results demonstrated that the cell viability and cell morphology were almost unchanged when treated with the range of experimental concentrations of Cur, regardless of the incubation time, indicating that Cur did not affect the growth of HDFs (data not shown). Subsequently, the cell viability of HDFs following exposure to UVA irradiation at 5,10 and $15 \mathrm{~J} / \mathrm{cm}^{2}$ intensities was determined. As demonstrated in Fig. 1A, at the $10 \mathrm{~J} / \mathrm{cm}^{2}$ dose of irradiation, cells underwent marked morphologic alterations observed under inverted microscope, including the development of a round cell shape, shrinkage and the presence of blebs, which is an established marker of cellular damage, on the surface of the cells. At the $15 \mathrm{~J} / \mathrm{cm}^{2}$ intensities, the morphological alterations of the cell became more severe. MTT assays demonstrated that the cell viability decreased in a dosage-dependent manner in response to UVA irradiation (Fig. 1B). Compared with the control group $\left(0 \mathrm{~J} / \mathrm{cm}^{2}\right)$, the cell viability of $10 \mathrm{~J} / \mathrm{cm}^{2}$ group decreased by $\sim 46 \%$ ( $\mathrm{P}<0.01$; Fig. 1B). However, $5 \mu \mathrm{M}$ Cur pretreatment for $2 \mathrm{~h}$ prior to exposure to $10 \mathrm{~J} / \mathrm{cm}^{2} \mathrm{UVA}$ irradiation prevented a UVA-induced reduction in cell viability (Fig. 1C) and no evident alterations in cell morphology were observed (data not shown), indicating that Cur may protect against photodamage. Therefore, $5 \mu \mathrm{M}$ Cur pretreatment for $2 \mathrm{~h}$ combined with $10 \mathrm{~J} / \mathrm{cm}^{2} \mathrm{UVA}$ irradiation were employed in the following experiments due to the optimal protective efficiency of this concentration of Cur in HDFs.

Cur inhibits the accumulation of UVA-induced ROS in HDFs. As UVA radiation induces phototoxicity by generating ROS, the present study investigated whether Cur may inhibit the accumulation of UVA-induced ROS. Cells with pretreatment of $5 \mathrm{mM}$ NAC were employed as a positive control for ROS protection. The results demonstrated that UVA irradiation alone led to a marked increase in the levels of ROS compared with the control group $(\mathrm{P}<0.01$; Fig. 1D), confirming that UVA induced the generation of ROS. However, compared with the control group, no marked alterations in the fluorescent signals were observed in cells treated with Cur alone, Cur + UVA irradiation or the NAC positive control (Fig. 1D). These results indicated that Cur inhibited the accumulation of UVA-induced ROS.

Effects of Cur on MDA levels and antioxidant proteins. As cells have natural antioxidative systems as a defense against high levels of ROS, the present study also measured the levels of MDA, an indicator of ROS, and the activity/levels of members of the cellular antioxidant defense system, including SOD, CAT and GSH, in the cells with or without Cur pretreatment. NAC was employed as the positive control described. The results demonstrated that the levels of MDA were increased, and the activities of SOD and CAT, and GSH levels, were significantly reduced, in the UVA irradiation alone group compared with the control group $(\mathrm{P}<0.01$; Fig. 1E-G). However, these effects of UVA on MDA, SOD, CAT and GSH were partially reversed in the Cur + UVA irradiation and NAC positive control groups compared with the UVA irradiation alone group $(\mathrm{P}<0.01$; Fig. $1 \mathrm{E}-\mathrm{G})$, indicating that Cur was able to restore the antioxidant capacities of HDFs subjected to UVA irradiation.

Cur inhibits endoplasmic reticulum (ER) stress in HDFs. As the accumulation of UVA-induced ROS often leads to ER stress, the present study further investigated whether the ER ultrastructure was altered under transmission electron microscopy. The results demonstrated that the morphological hallmarks of ER stress were represented by the expansion of the ER compartment, the shift from membrane-bound ribosomes to free forms and an increase in the large polysomes in the group treated with UVA irradiation alone, and such ultrastructural changes of the ER were not observed in the control, Cur alone or NAC positive control groups (Fig. 2A).

Furthermore, ER stress is closely associated with the activation of the unfolded protein response (UPR), which includes proteins such as GRP78 and CHOP (19). Therefore, the expression of these two proteins were determined by western blotting. 4-PBA, an ER stress inhibitor, was employed as the positive control. The results of western blotting revealed that the protein expression of GRP78 and CHOP was significantly increased in the group treated with UVA irradiation alone, compared with the control group ( $\mathrm{P}<0.01$; Fig. $2 \mathrm{~B}$ and $\mathrm{C})$. However, the levels of these two proteins were markedly decreased in the Cur + UVA irradiation group and 4-PBA positive control group, compared with the UVA irradiation alone group ( $\mathrm{P}<0.01$; Fig. $2 \mathrm{~B}$ and $\mathrm{C})$. These data indicated that Cur may prevent ER stress in HDFs upon exposure to UVA irradiation.

Cur protects HDFs against UVA-mediated apoptosis. The results of annexin V-FITC/propidium iodide staining followed by flow cytometry demonstrated that the total apoptosis rate in the group treated with UVA irradiation alone increased compared with the control group to $\sim 66.4 \%$; however, the total values were reduced to $\sim 38.2$ and $48.2 \%$ in the Cur + UVA irradiation and 4-PBA positive control groups, respectively, with the Cur + UVA irradiation group exhibiting a significantly lower total apoptosis value compared with the UVA irradiation alone group $(\mathrm{P}<0.01$; Fig. $3 \mathrm{~A}$ and $\mathrm{B})$. Furthermore, the expression of proteins associated with apoptosis was determined by western blotting. The results demonstrated that the cleaved caspase-3 protein expression was upregulated and the Bcl-2 expression downregulated in the group treated with UVA irradiation alone compared with the control group, while the levels of caspase-3 were 
A

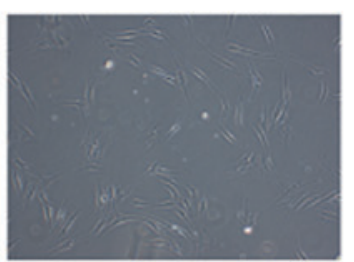

$0 \mathrm{~J} / \mathrm{cm}^{2}$

B
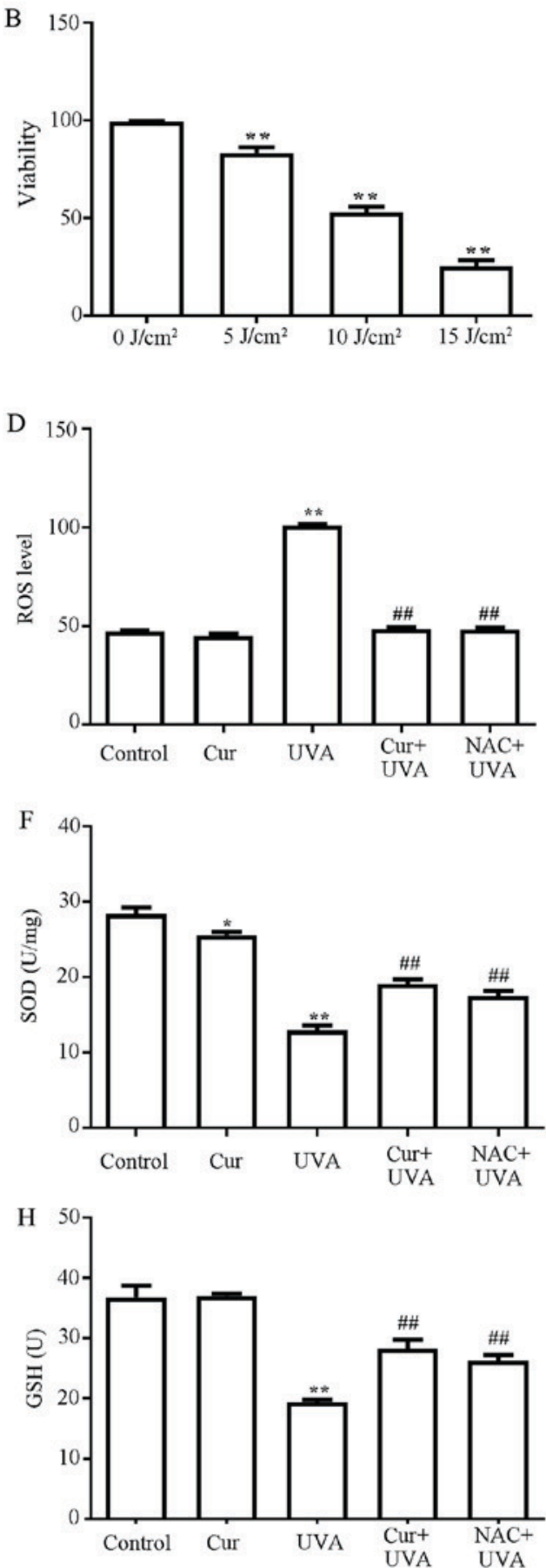

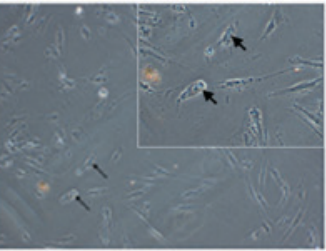

$10 \mathrm{~J} / \mathrm{cm}^{2}$

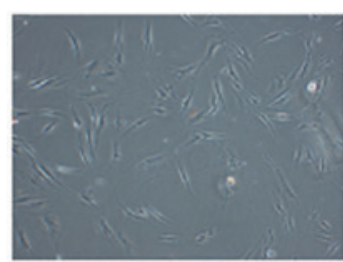

$15 \mathrm{~J} / \mathrm{cm}^{2}$
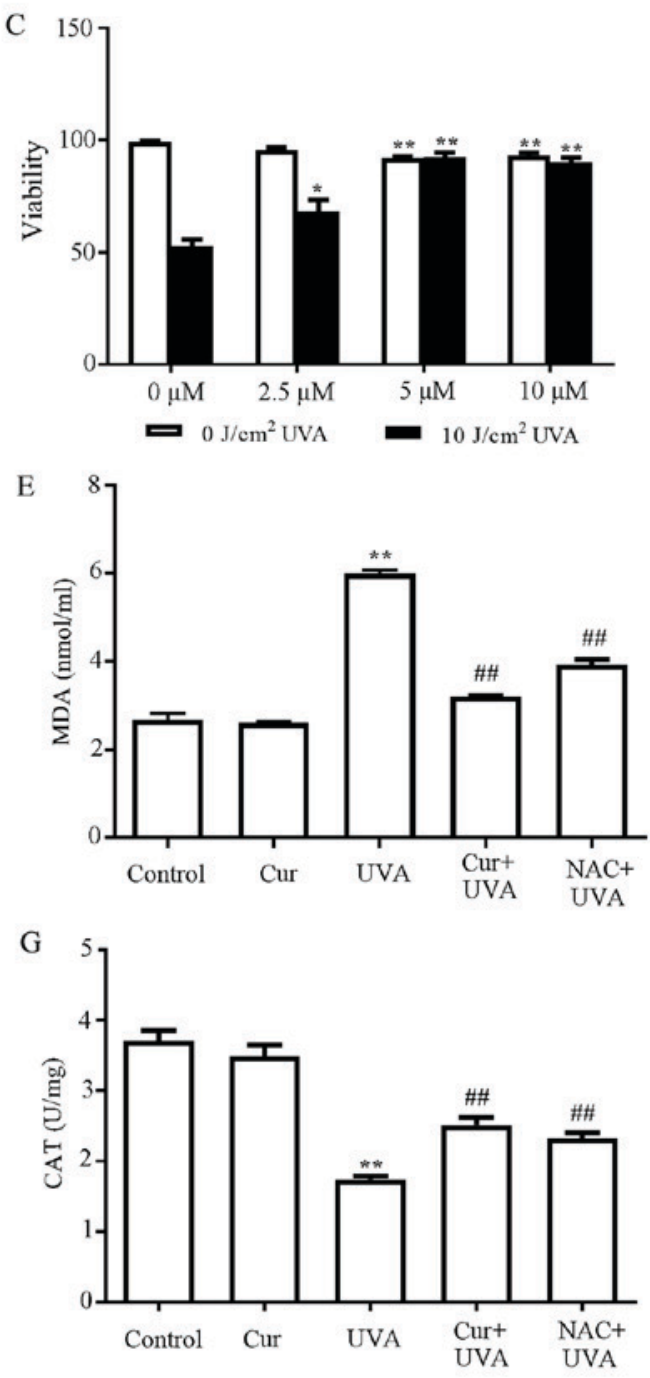

Figure 1. Cur inhibits UVA-induced damage in HDFs. (A) Cellular damage to HDFs induced by UVA irradiation at 0,10 and $15 \mathrm{~J} / \mathrm{cm}^{2}$ was observed by inverted microscopy, Magnification, $x 100$. Blebs were shown in the $10 \mathrm{~J} / \mathrm{cm}^{2}$ group (as indicate by the black arrowheads) and in the smaller square image on the top right corner of middle image $\left(10 \mathrm{~J} / \mathrm{cm}^{2}, \mathrm{x} 400\right)$. (B) Cell viability of HDFs treated with UVA irradiation at $0,5,10$ and $15 \mathrm{~J} / \mathrm{cm}^{2}$. ${ }^{* * *} \mathrm{P}<0.01 \mathrm{vs}$. $0 \mathrm{~J} / \mathrm{cm}^{2}$. (C) Cell viability of HDFs that were pretreated with $0,2.5,5$ and $10 \mu \mathrm{M}$ Cur for $2 \mathrm{~h}$, followed by exposure to $0 \mathrm{or} 10 \mathrm{~J} / \mathrm{cm}^{2} \mathrm{UVA}$. ${ }^{\# \#} \mathrm{P}<0.01 \mathrm{vs}$. control group without UVA irradiation; " $\mathrm{P}<0.05$ and ${ }^{* *} \mathrm{P}<0.01$ vs. control group with $10 \mathrm{~J} / \mathrm{cm}^{2} \mathrm{UVA}$ irradiation (D) Inhibitory effect of Cur on UVA-induced ROS accumulation in HDFs. The effects of Cur on UVA-induced alterations in (E) MDA levels, (F) SOD activity, (G) CAT activity and (H) GSH levels. All data are presented as the mean \pm standard deviation, $\mathrm{n}=3 .{ }^{*} \mathrm{P}<0.05$ and ${ }^{* *} \mathrm{P}<0.01$ vs. control group; ${ }^{\# \#} \mathrm{P}<0.01$ vs. UVA alone group. Cur, curcumin; UVA, ultraviolet $\mathrm{A} ; \mathrm{HDFs}$, human dermal fibroblasts; ROS, reactive oxygen species; MDA, malondialdehyde; SOD, superoxide dismutase; CAT, catalase; GSH, glutathione; NAC, N-acetyl cysteine. 

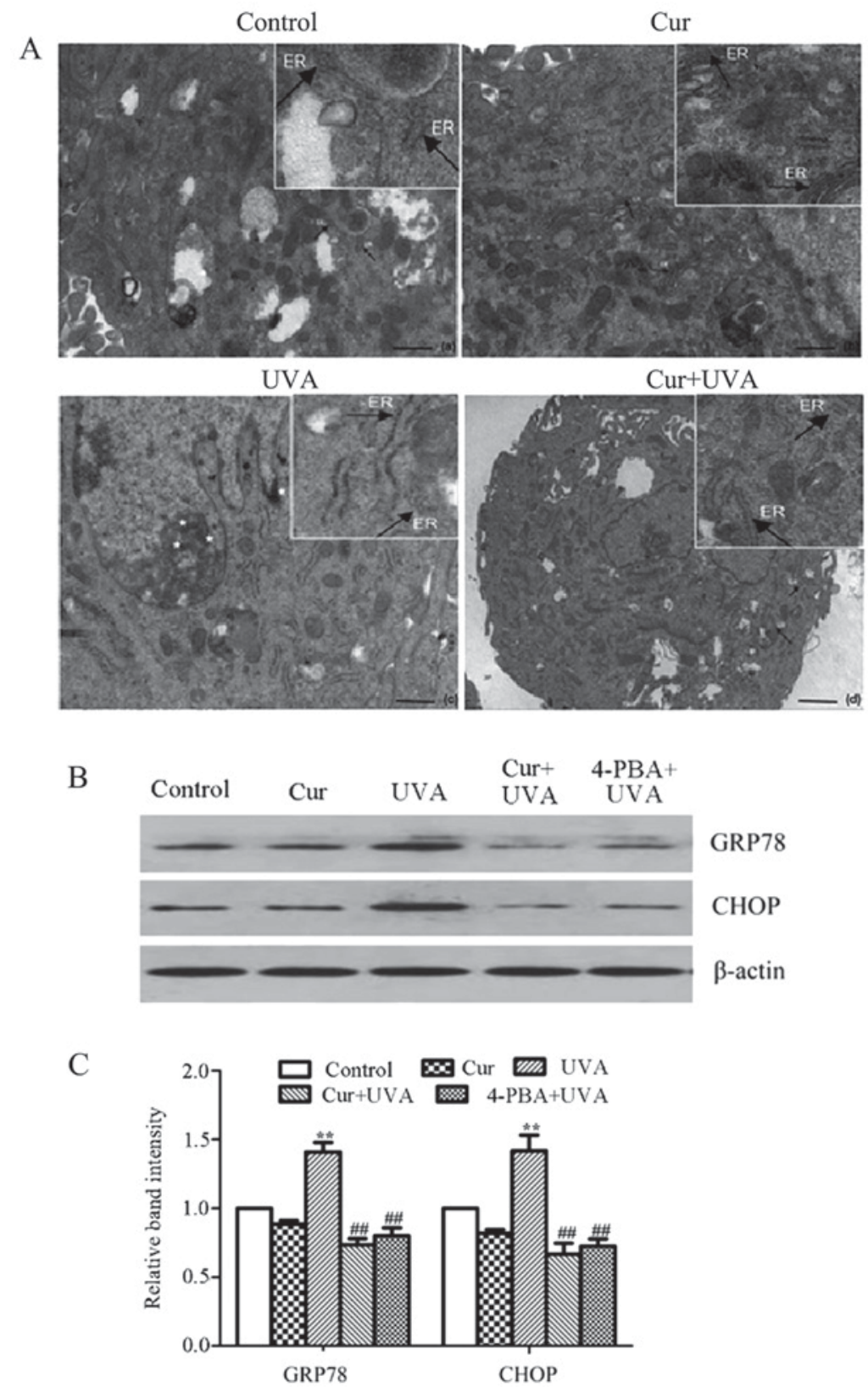

Figure 2. Cur inhibits UVA-induced ER Stress in human dermal fibroblasts. (A) Morphological alterations in the ER were observed by transmission electron microscopy in control, Cur, UVA and Cur + UVA groups. Scale bars: Control, Cur and UVA groups, $500 \mathrm{~nm}$; Cur + UVA group, $1 \mu \mathrm{M}$ (a different magnification is presented for the last group as a clear image could not be attained at the higher magnification). The areas of increased magnification within each image were taken directly from the larger image therefore the precise magnification cannot be stated. (B) Western blot analysis was performed to investigate the protein expression of GRP78 and CHOP using specific antibodies. (C) Relative expression of GRP78 and CHOP proteins was quantified by densitometry. All data are presented as the mean \pm standard deviation, $n=3$. ${ }^{* *} \mathrm{P}<0.01$ vs. control group; ${ }^{\# \#} \mathrm{P}<0.01$ vs. UVA group. Cur, curcumin; UVA, ultraviolet $\mathrm{A}$; ER, endoplasmic reticulum; GRP78, glucose-regulated protein 78; CHOP, C/EBP-homologous protein; 4-PBA, 4-phenylbutyric acid.

decreased and Bcl-2 increased in the Cur + UVA irradiation and 4-PBA positive control groups, compared with the UVA irradiation alone group (Fig. 3C and D). These data confirmed that Cur may attenuate apoptosis induced by UVA, as demonstrated by increases in the expression of the antiapoptotic protein, Bcl-2, and reduced caspase-3 levels.

Cur inhibits UVA-induced inflammation and collagen metabolism. It is established that UVA radiation results in inflammatory processes and the degradation of the collagen in the skin. Therefore, the present study also investigated the effects of Cur on the protein expression of NF-kB, MMP-1 and MMP-3, which are proteins implicated in inflammation and collagen metabolism in UVA-irradiated cells (20-22). NAC, which is also an inhibitor of the NF- $\mathrm{kB}$ signaling pathway, was employed as a positive control. The results of western blot analysis demonstrated that UVA irradiation alone promoted NF- $\mathrm{kB}, \mathrm{MMP}-1$ and MMP-3 expression compared with the control group $(\mathrm{P}<0.01$; Fig. 4A and B). However, combined treatment with Cur + UVA irradiation led to a moderate inhibitory effect on the induction of the expression of these three proteins, compared with the UVA irradiation alone group $(\mathrm{P}<0.05$; Fig. $4 \mathrm{~A}$ and $\mathrm{B})$, indicating that Cur may inhibit inflammation and restore normal collagen metabolism in HDFs exposed to UVA. 

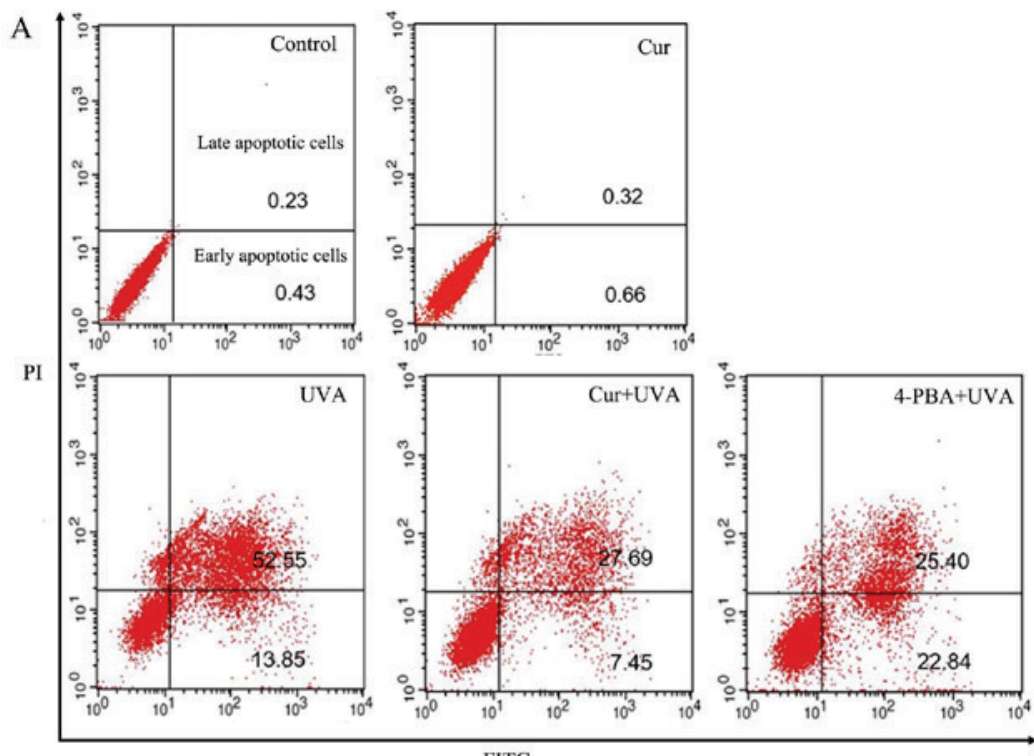

FITC

B
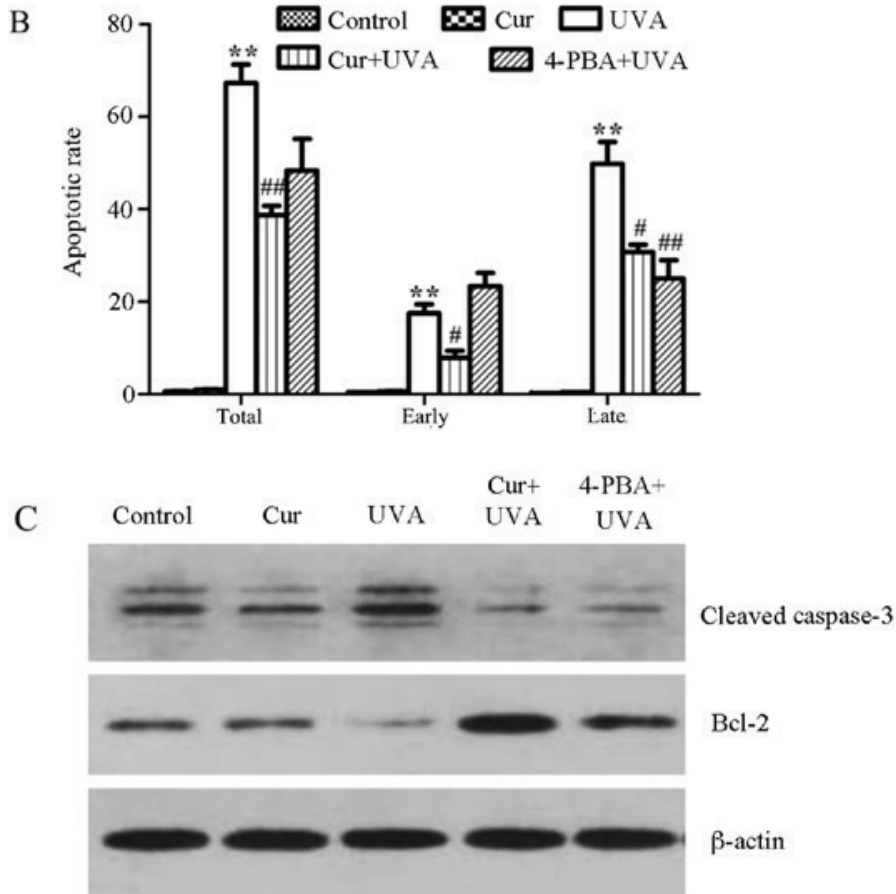

D

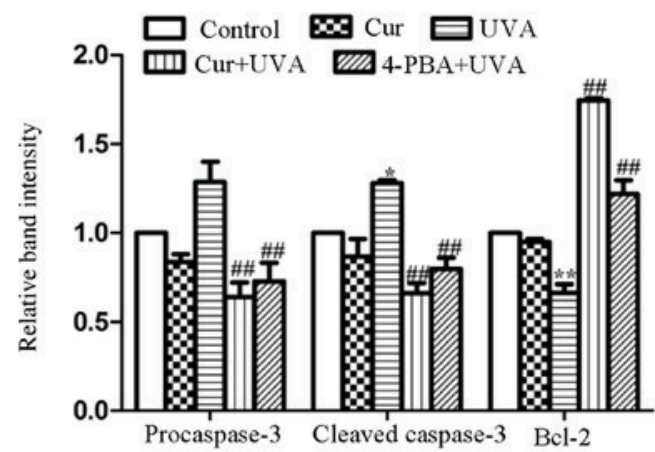

Figure 3. Cur protects against UVA-mediated apoptosis in human dermal fibroblasts. (A) Apoptosis levels were determined by an annexin V-FITC/PI double staining assay followed by flow cytometry. (B) Statistical analysis of the apoptotic rate of cells in various treatment groups. (C) Western blot analysis was performed to determine the protein expression of cleaved caspase-3 and Bcl-2 proteins using specific antibodies. (D) Relative expression of caspase- 3 and Bcl-2 proteins was quantified by densitometry. All data are presented as the mean \pm standard deviation, $n=3$. ${ }^{*} \mathrm{P}<0.05$ and ${ }^{* *} \mathrm{P}<0.01$ vs. control group; ${ }^{\#} \mathrm{P}<0.05$ and ${ }^{\# \#} \mathrm{P}<0.01$ vs. UVA group. Cur, curcumin; UVA, ultraviolet A; FITC, fluorescein isothiocyanate; PI, propidium iodide; 4-PBA, 4-phenylbutyric acid. 
A
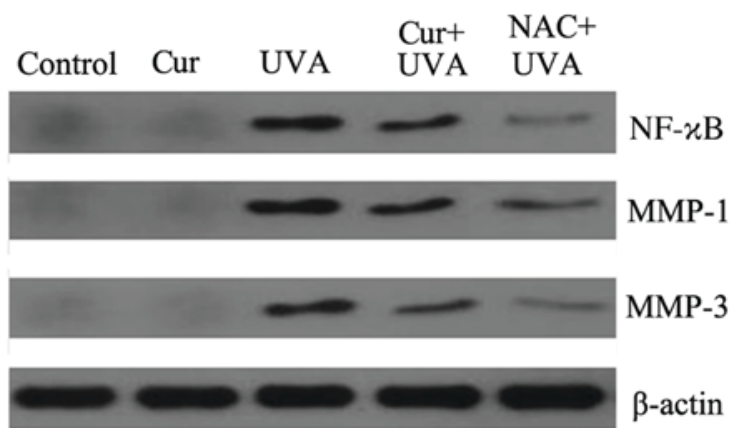

B

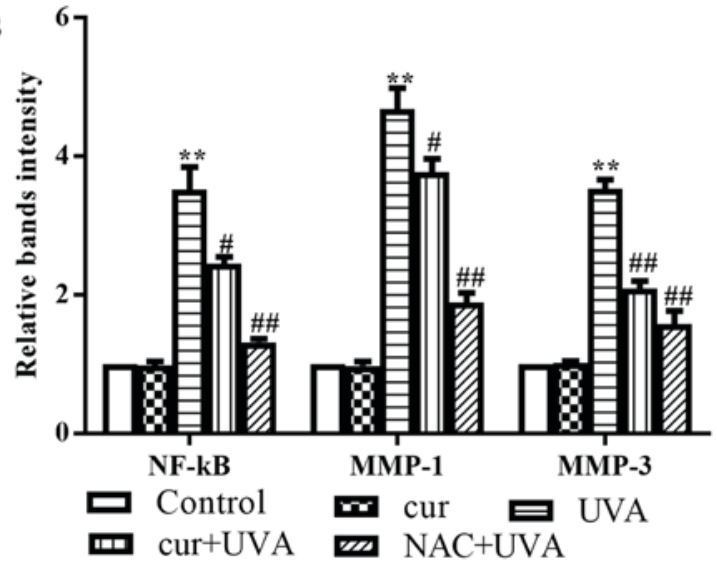

$\mathrm{C}$

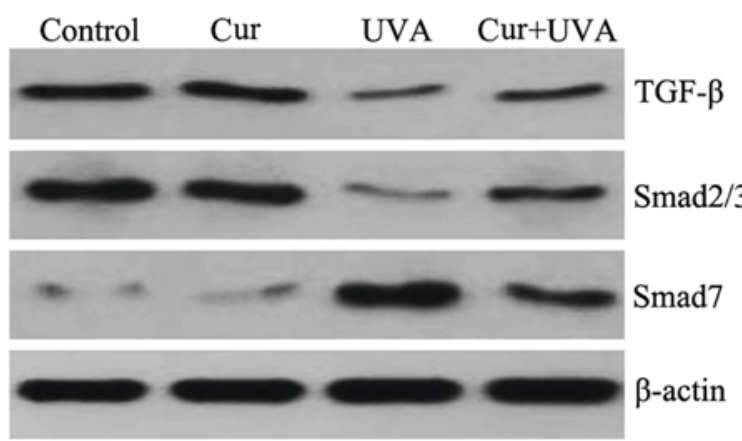

$\mathrm{D}$

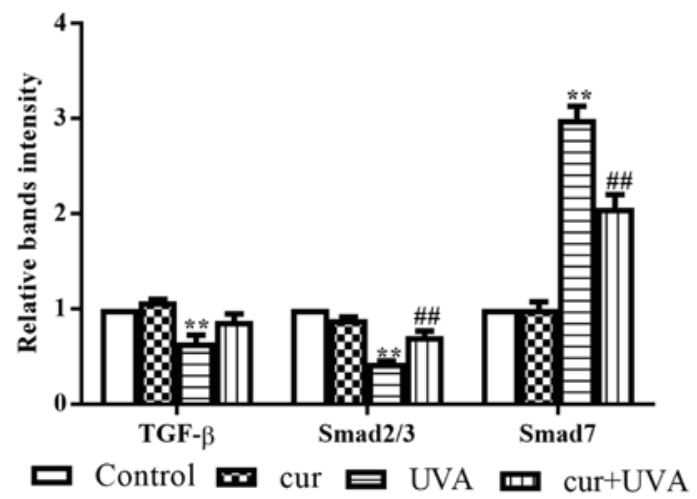

Figure 4. Effects of Cur on the expression of inflammation and collagen degradation-associated proteins in UVA-irradiated human dermal fibroblasts. (A) Western blot analysis was performed to investigate the protein expression of NF- $\kappa$ B, MMP-1 and MMP-3 using specific antibodies. (B) Relative expression of NF- $\mathrm{B}$, MMP-1 and MMP-3 proteins was quantified by densitometry. (C) Western blot analysis was performed to determine the protein expression of TGF- $\beta$, Smad $2 / 3$ and Smad7 using specific antibodies. (D) Relative expression of TGF- $\beta$, Smad $2 / 3$ and Smad7 proteins was quantified by densitometry. All data are presented as the mean \pm standard deviation, $n=3$. ${ }^{* *} \mathrm{P}<0.01$ vs. control group; ${ }^{\#} \mathrm{P}<0.05$ and ${ }^{\# \#} \mathrm{P}<0.01$ vs. UVA group. Cur, curcumin; UVA, ultraviolet $\mathrm{A} ; \mathrm{NF}-\kappa \mathrm{B}$, nuclear factor- $\kappa \mathrm{B}$; MMP, matrix metalloproteinase; TGF- $\beta$, transforming growth factor- $\beta$; NAC, $\mathrm{N}$-acetyl cysteine.
Effects of Cur on TGF- $\beta$ signaling. As UVA irradiation damages cells, we hypothesized that Cur may exert its protective effects on UVA-irradiated cells by promoting fibrogenesis. Increasing evidence has demonstrated that TGF- $\beta$ signaling is a key pathway in the process of wound repair, particularly for fibroblasts, and Smads are the regulators of the TGF- $\beta$ signaling pathway (23-25). Therefore, the present study further investigated the protein expression of TGF- $\beta, \operatorname{Smad} 2 / 3$ and Smad7 in the various treatment groups. Western blotting results demonstrated that the levels of TGF- $\beta$ and Smad2/3 in the UVA irradiation group were lower compared with the control group $(\mathrm{P}<0.01)$, while the levels of Smad7 were increased compared with the control group $(\mathrm{P}<0.01$; Fig. $4 \mathrm{C}$ and $\mathrm{D})$. However, the levels of Smad2/3 were upregulated, and Smad7 levels were downregulated, in the Cur + UVA irradiation group compared with the UVA irradiation alone group ( $\mathrm{P}<0.01$; Fig. $4 \mathrm{C}$ and $\mathrm{D})$. Interestingly, the level of TGF- $\beta$ expression in Cur+UVA group were not restored to the same degree as that of the control and Cur group alone, indicating that increase of Smad 2 and Smad3 expression might be independent from TGF- $\beta$ but through another signaling pathway, for example the mitogen-activated protein kinase 1 pathway $(26,27)$. The detailed mechanism requires further studies. These data indicated that Cur may stimulate the repair of UVA-induced damage in HDFs through regulating the TGF- $\beta$ pathway and the Smads that regulate the TGF- $\beta$ signaling pathway upon exposure to UVA irradiation.

\section{Discussion}

UVA-induced damage to cells has been the subject of numerous detailed studies. It is likely that UVA acts through an indirect mechanism that involves the absorption of photons by endogenous photosensitizers, which subsequently cause photo-oxidation reactions to produce ROS (28-31). Fortunately, various antioxidant defense systems are present in the skin, including GSH, CAT and SOD, which protect the skin against damage caused by UV-induced ROS to a certain extent (32). However, when ROS production exceeds the capacity of endogenous antioxidant systems to protect the target cell, oxidative stress develops, which has been associated with the onset and development of various disease states, including inflammation, photoaging and skin cancer (33). In the present study, UVA irradiation caused cell death in a dosage-dependent manner and led to the generation of increased levels of ROS. Additionally, an increase in MDA, which is an indicator of ROS, and reduced activities/levels of antioxidant proteins were also observed, which may be a result of increased ROS scavenging by the antioxidant systems upon UVA irradiation. When the cells were treated with Cur followed by UVA irradiation, the results demonstrated that the rate of cell death and ROS levels were decreased significantly, compared with the UVA irradiation alone group. Furthermore, a decrease in MDA also indicated the reduced levels of ROS following Cur pretreatment, and the levels of GSH, and CAT and SOD activities, were restored significantly following Cur pretreatment. These results indicated that the protective effect of Cur on HDFs may be due to an ability to scavenge UVA-induced ROS or 
an ability to increase the de novo synthesis of GSH, as previously reported by Sharma et al (34). Therefore, it may be plausible to employ Cur to inhibit or scavenge UVA-induced ROS so as to minimize the damage to cells.

ER stress, which may be characterized by the accumulation of unfolded or misfolded proteins in the ER, may occur due to alterations in calcium homeostasis, oxidative stress or inhibition of proteasomal activity in cells (35). To cope with ER stress, cells have developed a group of signal transduction pathways that are collectively termed the UPR, which facilitate the adaption of cells to ER stress $(36,37)$. Generally, the UPR pathways are mediated through three integral stress receptors, including inositol-requiring enzyme 1, pancreatic ER kinase-like ER kinase (PERK) and activating transcription factor 4 (ATF4) $(36,37)$. For example, under ER stress conditions, GRP78 becomes dissociated from PERK, which leads to PERK activation. Activated PERK promotes the translation of ATF4, which subsequently upregulates the expression of CHOP $(38,39)$. The present study demonstrated that the levels of the ER stress-associated proteins, GRP78 and CHOP, were increased significantly after HDFs were subjected to the UVA irradiation, confirming that ER stress was triggered by UVA. Furthermore, Cur pretreatment was able to downregulate the expression of GRP78 and CHOP compared with UVA-exposed cells without Cur pretreatment, indicating that Cur may protect HDFs against UVA-induced ER stress. To the best of our knowledge, no previous reports have demonstrated that Cur may attenuate UVA-induced ER stress by regulating the expression of proteins involved in the UPR.

It has been previously demonstrated that UVA radiation induced inflammatory responses as a result of the generation of ROS in UVA-exposed skin cells (40). NF- $\kappa \mathrm{B}$ has an important role in the development of inflammation and may serve as a marker of inflammation. The results of the current study clearly demonstrated that the expression of $N F-\kappa B$ was increased in HDFs treated with UVA irradiation alone, but was decreased in UVA-exposed HDFs with Cur pretreatment, indicating that Cur may inhibit the UVA-induced inflammation response. Furthermore, the results of flow cytometry results revealed that the rate of apoptosis was markedly increased following UVA irradiated alone, indicating that UVA induced cell damage and apoptosis in HDFs. Western blotting further confirmed the occurrence of the apoptosis following UVA, as reduced levels of the anti-apoptotic protein, Bcl-2, and increased levels of cleaved caspase-3, were observed following UVA treatment alone. However, pretreatment with Cur followed by UVA irradiation resulted in reduced apoptosis levels, which was also associated with reduced caspase- 3 and increased Bcl- 2 protein expression, compared with the UVA irradiation alone group, indicating that Cur may inhibit UVA-induced cell apoptosis by upregulating Bcl-2 and downregulating caspase-3 enzyme expression.

In addition to those results described above, other studies have reported that ROS was involved in the UVA-dependent induction of MMP-1, MMP-2 and MMP-3 mRNA and protein expression (41-44). In the present study, a significant decrease in the MMP-1 and MMP-3 levels was observed in the Cur + UVA irradiation group compared with the group treated with UVA irradiation alone. This indicates that Cur may exert its protective effect on the survival of cells by altering the matrix environment and regulating collagen metabolism. Alterations in collagen have been thought to be the characteristic alterations of photoaging (31). MMPs are involved in human skin photoaging through UV-induced collagen synthesis and degradation (45). The upregulation of MMPs, including MMP-1, MMP-2, as well as MMP-3, are mainly responsible for degrading of the collagen and elastin (46). TGF- $\beta$ is the major regulator that participates in wound repair, particularly within fibroblasts, in human skin $(47,48)$. The duration and intensity of the TGF- $\beta$ signaling pathway has been reported to be controlled through the phosphorylation of receptor-regulated Smad proteins (49-52); TGF- $\beta$ signaling is positively regulated by $\mathrm{Smad} 2 / 3$ and negatively regulated by Smad7. The results of the current study demonstrated that the protein expression of TGF- $\beta$ and $\mathrm{Smad} 2 / 3$ were reduced, while $\mathrm{Smad} 7$ expression was significantly increased, following UVA exposure, compared with the control group. However, in cells pretreated with Cur followed by UVA irradiation, the expression of TGF- $\beta$ and Smad2/3 was partially restored and Smad7 levels were reduced significantly, compared with the UVA irradiation alone group, indicating that Cur may protect HDFs against UVA-induced damage by enhancing fibroblast healing. These results demonstrated that TGF- $\beta, \operatorname{Smad} 2 / 3$ and $\operatorname{Smad} 7$ may have potential as novel targets through which Cur prevents UVA-induced photoaging in fibroblasts.

In conclusion, the present study demonstrated that Cur reduced the accumulation of UVA-induced ROS, restored the activities of antioxidative enzymes and attenuated ER stress, inflammation and apoptotic signaling. Additionally, Cur may also protect cells from photoaging by suppressing collagen degradation and enhancing collagen synthesis. All of these effects are helpful in the prevention of skin photoaging, indicating that Cur may be an effective therapeutic chemical for preventing the occurrence of UVA-induced skin aging and promoting cell repair. To the best of the authors' knowledge, the present study is the first to report that Cur may be beneficial in controlling the development of photoaging and for the promotion of the repair of UVA-induced damage. The results of the current study may lead to the development and application of Cur in the prevention of skin aging and improving the appearance of skin.

\section{Acknowledgements}

Not applicable.

\section{Funding}

The present study was supported by the CMA-L'OREAL China Skin Grant 2014 (grant no. S201411117), the Changzhou High-Level Medical Talents Training Project (grant no. 2016CZBJ034) and the Jiangsu Province's Preventive Medicine Science Foundation (grant no. Y2013020).

\section{Availability of data and materials}

All data generated or analyzed during this study is included in this published article. 


\section{Authors' contributions}

Conceived and designed the experiments: XLiu, RZ and XL. Performed the experiments: HS, AT and CX. Analyzed the data: YL. Wrote and revised manuscript: XL and XLiu.

\section{Ethics approval and consent to participate}

The present study was approved by the ethics committee of Soochow University (Changzhou, China) and written informed consent for the use of the child's foreskin in this study was obtained from the parent of the child.

\section{Consent for publication}

Not applicable.

\section{Competing interests}

The authors declare that they have no competing interests.

\section{References}

1. Parrish JA, Jaenicke RF and Anderson RR: Erythema and melanogenesis action spectra of normal human skin. Photochem Photobiol 36: 187-191, 1982.

2. Miller DL and Weinstock MA: Nonmelanoma skin cancer in the United States: Incidence. J Am Acad Dermatol 30: 774-778, 1994.

3. Kochevar IE: Molecular and cellular effects of UV radiation relevant to chronic photodamage. In: Bilchrest BA (ed). Photodamage. Blackwell, MA, pp51-58, 1995.

4. Jiang Y, Rabbi M, Kim M, Ke C, Lee W, Clark RL, Mieczkowski PA and Marszalek PE: UVA generates pyrimidine dimers in DNA directly. Biophys J 96: 1151-1158, 2009.

5. Heng MC: Curcumin targeted signaling pathways: Basis for anti-photoaging and anti-carcinogenic therapy. Int J Dermatol 49: 608-622, 2010

6. Brugè F, Damiani E, Puglia C, Offerta A, Armeni T, Littarru GP and Tiano L: Nanostructured lipid carriers loaded with CoQ10: Effect on human dermal fibroblasts under normal and UVA-mediated oxidative conditions. Int J Pharm 455: 348-356, 2013.

7. Offord EA, Gautier JC, Avanti O, Scaletta C, Runge F, Krämer K and Applegate LA: Photoprotective potential of lycopene, beta-carotene, vitamin $\mathrm{E}$, vitamin $\mathrm{C}$ and carnosic acid in UVA-irradiated human skin fibroblasts. Free Radic Biol Med 32: 1293-1303, 2002.

8. Wolosik K, Zareba I, Surazynski A and Markowska A: The possible pre- and post-UVA radiation protective effect of amaranth oil on human skin fibroblast cells. Pharmacogn Mag 13 (Suppl 2): S339-S343, 2017.

9. Jagetia GC and Aggarwal BB: 'Spicing up' of the immune system by curcumin. J Clin Immunol 27: 19-35, 2007.

10. Ammon $\mathrm{H}$ and Wahl MA: Pharmacology of Curcuma longa. Planta Med 57: 1-7, 1991

11. Tilak J, Banerjee M, Mohan $\mathrm{H}$ and Devasagayam PA: Antioxidant availability of turmeric in relation to its medicinal and culinary uses. Phytother Res 18: 798-804, 2004.

12. Azuine MA and Bhide SV: Chemopreventive effect of turmeric against stomach and skin tumors induced by chemical carcinogens in Swiss mice. Nutr Cancer 17: 77-83, 1992.

13. Huang M, Smart RC, Wong CQ and Conney $\mathrm{AH}$ Inhibitory effect of curcumin, chlorogenic acid, caffeic acid, and ferulic acid on tumor promotion in mouse skin by 12-O-tetradecanoylphorbol-13-acetate. Cancer Res 48: 5941-5946, 1988.

14. Inano H, Onoda M, Inafuku N, Kubota M, Kamada Y, Osawa T, Kobayashi $\mathrm{H}$ and Wakabayashi K: Chemoprevention by curcumin during the promotion stage of tumorigenesis of mammary gland in rats irradiated with gamma-rays. Carcinogenesis 20: 1011-1018, 1999.
15. Inano H, Onoda M, Inafuku N, Kubota M, Kamada Y, Osawa T, Kobayashi $\mathrm{H}$ and Wakabayashi K: Potent preventive action of curcumin on radiation-induced initiation of mammary tumorigenesis in rats. Carcinogenesis 21: 1835-1841, 2000.

16. Hwang BM, Noh EM, Kim JS, Kim JM, You YO, Hwang JK, Kwon KB and Lee YR: Curcumin inhibits UVB-induced matrix metalloproteinase-1/3 expression by suppressing the MAPK-p38/JNK pathways in human dermal fibroblasts. Exp Dermatol 22: 358-379, 2013.

17. Tsai KD, Lin JC, Yang SM, Tseng MJ, Hsu JD, Lee YJ and Cherng JM: Curcumin protects against UVB-induced skin cancers in SKH-1 hairless mouse: Analysis of early molecular markers in carcinogenesis. Evid Based Complement Alternat Med 2012: 593952, 2012.

18. Li JK and Lin-Shiau SY: Mechanisms of cancer chemoprevention by curcumin. Proc Natl Sci Counc Repub China B 25: 59-66, 2001.

19. Szegezdi E, Logue SE, Gorman AM and Samali A: Mediators of endoplasmic reticulum stress-induced apoptosis. EMBO Rep 7: 880-885, 2006

20. Fisher GJ, Wang Z, Datta SC, Varani J, Kang S and Voorhees JJ: Pathophysiology of premature skin aging induced by ultraviolet light. N Engl J Med 337: 1419-1428, 1997.

21. Polte T and Tyrrell RM: Involvement of lipid peroxidation and organic peroxides in UVA-induced matrix metalloproteinase-1 expression. Free Radic Biol Med 36: 1566-1574, 2004.

22. Brennan M, Bhatti H, Nerusu KC, Bhagavathula N, Kang S, Fisher GJ, Varani J and Voorhees JJ: Matrix metalloproteinase-1 is the major collagenolytic enzyme responsible for collagen damage in UV-irradiated human skin. Photochem Photobiol 78: 43-48, 2003.

23. Liu W, Wang DR and Cao YL: TGF-beta: A fibrotic factor in wound scarring and a potential target for anti-scarring gene therapy. Curr Gene Ther 4: 123-136, 2004.

24. Kopp J, Preis E, Said H, Hafemann B, Wickert L, Gressner AM, Pallua $\mathrm{N}$ and Dooley S: Abrogation of transforming growth factor-beta signaling by SMAD7 inhibits collagen gel contraction of human dermal fibroblasts. J Biol Chem 280: 21570-21576, 2005.

25. Lan HY: Diverse roles of TGF- $\beta /$ Smads in renal fibrosis and inflammation. Int J Biol Sci 7: 1056-1067, 2011.

26. Li JH, Huang XR, Zhu HJ, Oldfield M, Cooper M, Truong LD, Johnson RJ and Lan HY: Advanced glycation end products activate Smad signaling via TGF-beta-dependent and independent mechanisms: Implications for diabetic renal and vascular disease. Faseb J 18: 176-178, 2004

27. Chung AC, Zhang H, Kong YZ, Tan JJ, Huang XR, Kopp JB and Lan HY: Advanced glycation end-products induce tubular CTGF via TGF-beta-independent Smad3 signaling. J Am Soc Nephrol 21: 249-260, 2010.

28. Douglas RH, Moan J and Rontb G (eds): Light in Biology and Medicine, Plenum, New York 2, 1991.

29. Cadet J, Berger M, Douki T, Morin B, Raoul S, Ravanat JL and Spinelli S: Effects of UV and visible radiation on DNA-final base damage. Biol. Chem 378: 1275-1286, 1997.

30. Cadet J, Berger M, Decarroz C, Wagner JR, van Lier JE, Ginot YM and Vigny P: Photosensitized reactions of nucleic acids. Biochimie 68: 813-834, 1986.

31. Fisher GJ, Kang S, Varani J, Bata-Csorgo Z, Wan Y, Datta S and Voorhees JJ: Mechanisms of photoaging and chronological skin aging. Arch Dermatol 138: 1462-1770, 2002.

32. Afaq F and Mukhtar H: Effects of solar radiation on cutaneous detoxification pathways. J Photochem Photobiol B 63: 61-69, 2001.

33. Shindo Y, Witt E and Packer L: Antioxidant defense mechanisms in murine epidermis and dermis and their responses to ultraviolet light. J Invest Dermatol 100: 260-265, 1993.

34. Sharma RA, Ireson CR, Verschoyle RD, Hill KA, Williams ML, Leuratti C, Manson MM, Marnett LJ, Steward WP and Gescher A: Effects of dietary curcumin on glutathione S-transferase and malonaldehyde-DNA adducts in rat liver and colon mucosa: Relationship with drug levels. Clin Cancer Res 7: 1452-1458, 2001

35. Zhang KZ and Kaufman RJ: From endoplasmic-reticulum stress to the inflammatory response. Nature 454: 455-462, 2008.

36. Ron D and Walter P: Signal integration in the endoplasmic reticulum unfolded protein response. Nat Rev Mol Cell Biol 8: 519-529, 2007.

37. Schröder M and Kaufman RJ: The mammalian unfolded protein response. Annu Rev Biochem 74: 739-789, 2005.

38. Lu PD, Harding HP and Ron D: Translation reinitiation at alternative open reading frames regulates gene expression in an integrated stress response. J Cell Biol 167: 27-33, 2004. 
39. Harding HP, Novoa I, Zhang Y, Zeng H, Wek R, Schapira M and Ron D: Regulated translation initiation controls stress-induced gene expression in mammalian cells. Mol Cell 6: 1099-1108, 2000.

40. Soter NA: Sunburn and suntan: Immediate manifestations of photodamage. In: Gilchrest BA (ed). Photodamage. Cambridge (MA), Blackwell Science: 12-25, 1995.

41. Herrmann G, Wlaschek M, Bolsen K, Prenzel K, Goerz G and Scharffetter-Kochanek K: Pathogenic implication of matrix-metalloproteinases (MMPs) and their counteracting inhibitor TIMP-1 in the cutaneous photodamage of human porphyria cutanea tarda (PCT). J Invest Dermatol 107: 398-403, 1996.

42. Wlaschek M, Briviba K, Stricklin GP, Sies $H$ and Scharffetter-Kochanek K: Singlet oxygen may mediate the ultraviolet A-induced synthesis of interstitial collagenase. J Invest Dermatol 104: 194-198, 1995.

43. Scharffetter-Kochanek K, Wlaschek M, Briviba K and Sies H: Singlet oxygen induces collagenase expression in human skin fibroblasts. FEBS Lett 331: 304-306, 1993.

44. Wenk J, Brenneisen P, Wlaschek M, Poswig A, Briviba K, Oberley TD and Scharffetter-Kochanek K: Stable overexpression of manganese superoxide dismutase in mitochondria identifies hydrogen peroxide as a major oxidant in the AP-1-mediated induction of matrix-degrading metalloproteinase-1. J Biol Chem 274: 25869-25876, 1999.

45. Pandel R, Poljšak B, Godic A and Dahmane R: Skin photoaging and the role of antioxidants in its prevention. ISRN Dermatol 2013: 930164, 2013.
46. Erman H, Gelisgen R, Cengiz M, Tabak O, Erdenen F and Uzun H: The association of vascular endothelial growth factor, metalloproteinases and their tissue inhibitors with cardiovascular risk factors in the metabolic syndrome. Eur Rev Med Pharmacol Sci 20: 1015-1022, 2016

47. Kryger ZB, Sisco M, Roy NK, Lu L, Rosenberg D and Mustoe TA: Temporal expression of the transforming growth factor-Beta pathway in the rabbit ear model of wound healing and scarring. J Am Coll Surg 205: 78-88, 2007.

48. Leask A and Abraham DJ: TGF-beta signaling and the fibrotic response. FASEB J 18: 816-827, 2004.

49. Massagué J: TGF-beta signal transduction. Annu Rev Biochem 67: 753-791, 1998

50. Massagué $\mathrm{J}$ and Chen YG: Controlling TGF-beta signaling. Genes Dev 14: 627-644, 2000.

51. Massagué J and Wotton D: Transcriptional control by the TGF-beta/Smad signaling system. EMBO J 19: 1745-1754, 2000.

52. Piek E, Heldin $\mathrm{CH}$ and Ten Dijke P: Specificity, diversity, and regulation in TGF-beta superfamily signaling. FASEB J 13: 2105-2124, 1999.

(i) (9) This work is licensed under a Creative Commons Attribution-NonCommercial-NoDerivatives 4.0 International (CC BY-NC-ND 4.0) License. 